\title{
Thank you, Richard Rose
}

This issue of Powder Diffraction is the first one to be processed and printed by the American Institute of Physics. For the previous seven years, from the inception of Powder Diffraction, these activities have been under the guidance of Richard N. Rose, without whose services the journal would never have reached the professional quality and international recognition that it enjoys today. It was a fortunate set of circumstances, in 1985, when Dick retired from Philips Electronics Instruments with over 30 years of experience with the Norelco Reporter among his many accomplishments. He had just the right background, including a knowledge of powder diffraction, to help the founders of the journal get it through its critical years. Fortunately for Powder Diffraction, he was not yet ready to fully retire, and he readily accepted the challenge of starting a new publication.

With Dick's guidance, Powder Diffraction has done more than create a much needed new publication. It has advanced to its present status of world-wide recognition as the international medium for disseminating scientific information on powder diffraction methods and applications. Dick's role has been mostly behind the scenes, where the readers usually do not notice all the effort that is required to get the manuscripts, which have cleared the editors, organized and formatted for the final publication. He made sure that all the parts of the journal-the advertisements, the Editorial, the International Report, and the articleswere in hand and assembled and laid out for the printing firm. He contacted delinquent authors for improvements on figures and other missing information. He was the final copy editor on grammar and style, especially the problems imposed to maintain a consistent format of presentation of the articles. He was always aware of the various copy deadlines and printer schedules, and kept the rest of the staff on our toes to meet those deadlines. Much of the appearance of Powder Diffraction, and the selection of paper stock that makes the journal easy to read, were decisions based on Dick's recommendations.

Dick has prepared a few of the articles for publication. Following the recommendation of the staff for an historical article, Dick would make sure that the presentation of the article would do justice to its importance. Usually the tables, and especially the figures, would require much effort to reproduce clearly. Dick also prepared some human interest profiles of early researchers in powder diffraction such as C. S. Barrett (Vol. 2, pp. 163-175), J. D. Hanawalt (Vol. 5, pp. 70-75), and B. Post (Vol. 5, pp. 131-136). He was also the main critic on the Editorials prepared by members of the Editorial Staff.

Another important role played by Dick was the monitoring of the contract printers. One goal of Powder Diffraction has been to keep the subscription price at a level where individuals could afford copies for their own use. One of the major expenses is the printer. Dick monitored the printers and kept the journal expenses from being inflated by escalating printer charges, by recommending the best printers each year and monitoring the new printers to maintain the quality.

The magnitude of Dick's role can be exemplified by considering that a whole organization, AIP, is essentially taking over for him. Although Dick will be retained as a consultant for a while during the early stages of the AIP transition, he can now fully retire and enjoy the Vermont countryside he calls home, without worrying about those deadlines. The staff of Powder Diffraction extends to Dick a sincere thanks for all that he has done to make our journal such a success. May your years of full retirement be many and relaxing. They are well deserved.

Deane K. Smith, Editor-in-Chief
Ron Jenkins, Managing Editor 